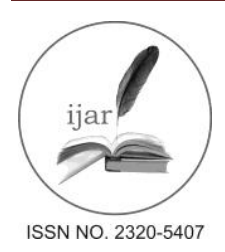

Journal homepage: http://www.journalijar.com

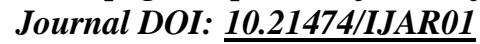

INTERNATIONAL JOURNAL

OF ADVANCED RESEARCH

RESEARCH ARTICLE

\title{
COMPACT SIZE FRACTAL ANTENNA DESIGN USING STRIPES TO INCREASES ANTENNA LENGTH FOR ISM AND HIGHER FREQUENCY APPLICATIONS.
}

\author{
Er. Jitin Verma ${ }^{1}$ and Dr. Nerru Malhotra ${ }^{2}$. \\ 1. St. Soldier Polytechnic College, Jalandhar. \\ 2. HoD (DAVIET), Jalandhar.
}

Manuscript Info
..........................................................
Manuscript History:
Received: 12 May 2016
Final Accepted: 22 June 2016
Published Online: July 2016
Key words:
.Corresponding Author
.....................
Er. Jitin Verma.

\section{Manuscript Info}

Manuscript History:

Received: 12 May 2016

Final Accepted: 22 June 2016

Key words:

Er. Jitin Verma.

\begin{abstract}
Multi-band antenna is designed by using stripes of $2 \mathrm{~mm}$ in width and finite length to give a square shapes. In which the four different sizes of squares are combine together to form a microstripe patch fractal antenna to increase the antenna length so as to get more surface for maximum current distribution. The different iterations fractal configuration is shown along with simulation results are presented. This antenna is used for an application in ISM and higher frequency bands.
\end{abstract}

\section{Introduction:-} Introduction:-

The antennas with multiple frequencies and smaller dimensions than conventional ones are preferred. Various methodologies have been studied in the antenna research to compress the size and to achieve multi-band characteristics in a single patch. Multiple bands with good gain \& radiation in a single patch are not easily achievable in simple microstrip antenna. A review of various techniques to reduce the antenna size is given in Ref. [1]. In [2] simulation of the patch antenna is obtained by using and merging techniques, inserting slots as inductive loading and making some short point in the middle of the patch. In [3] a design is proposed to reduce the size of a microstrip patch antenna and another technique is employed to achieve antenna size reduction by increasing the electrical length of the antenna [4]. Many research papers have reported for achieving dual band operation of microstrip antennas. A novel design of a dual band planar monopole antenna, consisting of a rectangular strip ring with double meander-lines and a top loaded vertical strip, is presented in [5]. In [6] slot antennas were used to achieve multiband characteristics. In [8] multi-band probe fed stacked patch antenna for GPS is given which is intensively used both in civilian and military application.

\section{Fractal Antennas:-}

Recently fractal techniques have been widely used in antenna design so that the antenna size is reduced and to achieve multi-band behavior. Fractal antennas are physically small but electrically longer in lengths in small packages. Various geometries have been utilized to develop fractal antennas in order to have multi-band characteristics and miniaturization. Much intensive researches have been done in recent years to develop fractal antennas: long periodic fractal Koch antenna [9] and bow shaped fractal helix antenna [10]. A modified Minkowski fractal geometry for multiband operation is presented in [11]. Koch-like curve and Sierpinski Gasket are synchronized in a way, comprising so called Sierpinski Koch-like sided bow-tie (SKLB) multi-fractal to achieve size reduction and multi-frequency use [12]. A plus shaped slotted fractal antenna with first and second iteration is reported in [13] that gives a good size reduction and enhanced band width. Fractal geometry composed of multiple iterations of a single elementary shape. This compact \& advance in property is highly attractive in mobile wireless applications. The advantages of fractal antenna compared with a standard microstrip antenna are their high gain and bandwidth 


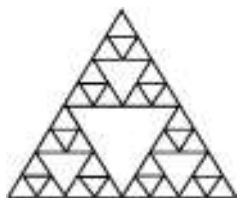

Sierpinski Gasket

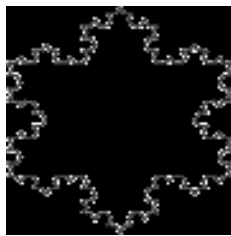

Koch Curve

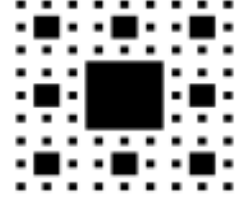

Sierpinski Carpet

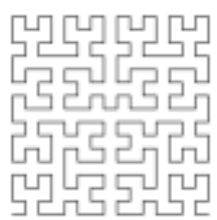

Hilbert Curve

Figure 1: Fractal antennas

Today there is rapid development of mobile communication systems and devices operating at multiple frequency bands have led to the requirement of antennas which support multi-band or wideband operation. Various wireless communication services have been available which may use frequency spectrum allocation like ISM band along with K band system. This leads to development of multi-band antennas, where lower as well as higher frequencies can be used simultaneously. Various research papers have reported about dual band antennas that are suitable for above mentioned application [19] [20]. The ISM standard has the advantage of allowing wireless connection between a base transceiver station and thousands of subscribers without requiring the subscriber to be in a direct line of sight with the station, called non line of sight communication [NLOS]. The advantage of multi-band antenna is the ability to integrate several frequency bands on one single antenna, making it useful for several frequency ranges. In this paper, stripes are used with finite dimensions as fractal microstrip antenna for multi-band applications. This concept is introduced into a square and plus shaped microstrip patch antenna to obtain multi-band behavior and miniaturization. This square shaped dual band fractal microstrip patch antenna resonates at $2.58 \mathrm{GHz}$ to $6.24 \mathrm{GHz}$ and $14.88 \mathrm{GHz}$ to $16.73 \mathrm{GHz}$. The first frequency is used for ISM band and the second frequency is used for $\mathrm{K} \& \mathrm{Ku}$ band applications. In order to obtain antenna, with optimized parameters, simulation studies were carried out using high frequency structure simulator (HFSS).

\section{Antenna Configuration:-}

The antenna is fabricated by using the FR-4 substrate which is having the thickness $1.6 \mathrm{~mm}$, relative permittivity of 4.4 and dielectric constant 0.02 .The multiple iterations have taken place to design thee fractal antenna which is having the overall outer dimension of $34 \mathrm{~mm}$ each side whereas the smallest square which is subtracted from it of $2 \mathrm{~mm}$ each and other design specifications are given in table 1.The antenna is fed by co-axial feed at the edge of the outermost shell to have good radiation pattern and multiple bands. Multiple resonance frequencies are shown in table 3 . Where return loss less than $-10 \mathrm{db}$ at frequencies from $2.58 \mathrm{GHz}-16.73 \mathrm{GHz}$ so as to obtain the maximum overall bandwidth. The design of an antenna was optimized using HFSS 13.2 simulator to get better results. The lower resonant frequency is suitable for ISM band, whereas upper/higher frequencies for K \& Ku band or wireless access networks.

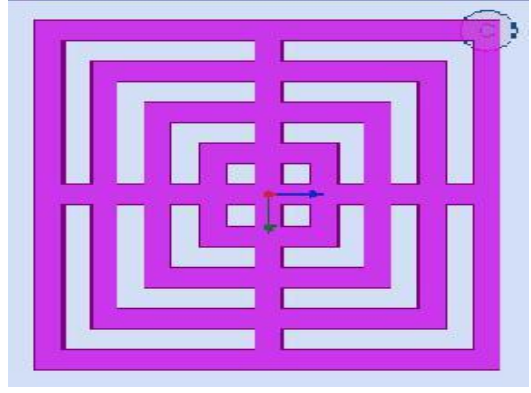

Figure 2 Antenna design 


\begin{tabular}{|l|l|l|l|}
\hline & \multicolumn{2}{|c|}{ Table 1: Antenna dimensions } & \\
\hline Label & \multicolumn{1}{|c|}{ Dimensions (in mm) } & \\
\hline A & 34 \\
\hline B & 26 & \\
\hline C & 18 & \\
\hline D & 10 & \\
\hline E & & 2 & \\
\hline
\end{tabular}

\section{Results and Discussions:-}

Figure 3shows the simulated results of the return loss variation with frequency and gain for the given fractal patch antenna. It can be seen that at $-10 \mathrm{~dB}$ the bandwidth is measured from starting frequency $2.58 \mathrm{GHz}$ to $16.73 \mathrm{GHz}$ as shown in table 2 or below -10db multiple frequencies and bandwidth can be seen in frequency response curve, which can be used for many wireless communication systems or for different frequency bands. By using fractal geometry on behalf of simple square antenna the size is reduced and length for current distribution is increased.

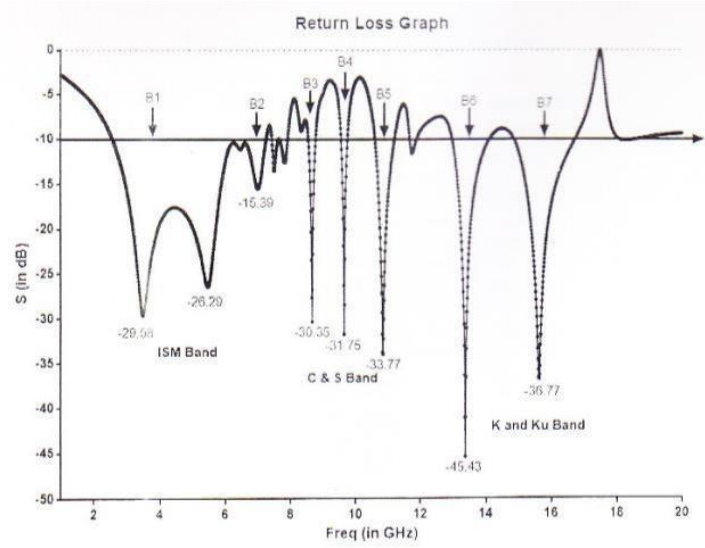

Figure 3:Simulated return loss for the designed antenna.

Table 2: Return Loss Graph Analysis

\begin{tabular}{|l|l|l|l|}
\hline Sr.no. & Start & Stop & Bandwidth \\
\hline & frequency ( & frequency & (approximation) \\
\hline & GHz) & (GHz) & \\
\hline B1 & 2.58 & 6.24 & $3.66 \mathrm{GHz}$ \\
\hline B2 & 6.62 & 7.24 & $620 \mathrm{MHz}$ \\
\hline B3 & 8.55 & 8.77 & $220 \mathrm{MHz}$ \\
\hline B4 & 9.56 & 9.75 & $200 \mathrm{MHz}$ \\
\hline B5 & 10.61 & 11.23 & $620 \mathrm{MHz}$ \\
\hline B6 & 12.98 & 14.12 & $1.4 \mathrm{GHz}$ \\
\hline B7 & 14.88 & 16.73 & $1.85 \mathrm{G} \mathrm{Hz}$ \\
\hline
\end{tabular}

The radiation pattern is a graphical representation of the characteristics of an antenna radiation in a certain direction. These characteristics include radiation intensity, field intensity and polarization. It is normally represented with rectangular or polar plots and it is expressed in $\mathrm{dB}$ radiation pattern is a plane cut and represents one frequency and one polarization. The Radiation pattern of this antenna shows that the maximum energy is radiated towards theta $=0$ and creates an equal power distribution in that particular direction and its values are given in table 3 .

Table: Return Loss wrt Resonance Frequency

\begin{tabular}{|l|l|l|}
\hline SR.NO & RESONANCE FREQUENCY $(\mathrm{GHz})$ & RETURN LOSS $(\mathrm{dB})$ \\
\hline 1 & 3.50 & -29.58 \\
\hline 2 & 5.47 & -26.43 \\
\hline 3 & 7.00 & -15.52 \\
\hline 4 & 8.66 & -30.35 \\
\hline 5 & 9.65 & -31.75 \\
\hline 6 & 10.85 & -33.98 \\
\hline 7 & 13.37 & -45.43 \\
\hline 8 & 16.62 & -36.77 \\
\hline
\end{tabular}




\section{Conclusion:-}

The designed striped square shaped fractal microstrip patch antenna has established it's prospective for all frequency bands for multi-functioning. The antenna generates many different frequencies for resonating modes, which are focused at the measured frequencies from $2.58 \mathrm{GHz}$ to $16.73 \mathrm{GHz}$; the multiple bands antenna find its applications in mobile phone communication and in Wi-MAX or other wireless access. The designed multi-band multi-frequency antenna provides reasonable gain \& the radiation patterns are also virtuous for all wireless applications.

\section{References:-}

1. Constantine A. Balanis, Antenna theory analysis and design, $2^{\text {nd }}$ edition, John Wiley \&sons, Inc, 1997

2. Rachmansyah, Antonius Irianto, and A. Benny Mutiara, "Designing and Manufacturing Microstrip Antenna for Wireless Communication at $2.4 \mathrm{GHz}$," International Journal of Computer and Electrical Engineering, Vol. 3, No. 5, October 2011.

3. D. Orban and G.J.K Moernaut, "The Basic of Patch Antenna."

4. K. R Carver and J. W Mink. "Microstrip Antenna Technology" In: IEEE Trans. Antennas Propagate. Vol.AP29.no.1 (1981), pp. 2-24.

5. Gurdeep Singh" Comparative Analysis of Microstrip Patch Antenna With Different Feeding Techniques"

6. International Conference on Recent Advances and Future Trends in Information Technology (iRAFIT2012) Proceedings published in International Journal of Computer Applications ${ }^{\circledR}$ (IJCA)

7. SubhrakantaBehera\&DebaprasadBarad A Novel Design Of Micro Strip Fractal Antenna for Wireless Sensor

8. Network"In International Conference On Computation Of Power, Energy, Information And Communication. 2015

9. Yabing Shi and Wenjun Zhang "High-Gain Stacked Minkowski Fractal Patch Antenna with Superstrate for 60GHz Communications" Institute of Microelectronics of Tsinghua University, 10084 Beijing, China

10. DethaliaAnkitkumarManjibhai, Prof. Jayeshkumar C. Prajapati, Dipakkumar J. Barasara "An Overview of

11. Fractal Geometries and Antenna" International Journal of Engineering and Science ISSN: 2278-4721, Vol. 1, Issue 2(Sept 2012), PP 01-04 A. N. Bogolyubov "Analysis and Synthesis of Fractal Antenna Radiation Patterns" ISSN 0027_1349, Moscow University Physics Bulletin, 2009, Vol. 64, No. 6, pp. 561-568. ( ) Allerton Press, Inc., 2009.Original Russian Text (C) A.N. Bogolyubov, A.A. Koblikov, N.E. Shapkina, 2009, published in VestnikMoskovskogoUniversiteta. Fizika, 2009, No. 6, pp. 3-10.

12. Jacob Abraham, Thomaskutty Mathew "Dual Band David Fractal Microstrip Patch Antenna for GSM and WiMAX Applications" Wireless Engineering and Technology, 2015, 6, 33-40

13. Jean-Francois, Zurcher Fred, E.Gardiol, "Broadband Patch Antennas," Artech house, Boston, London

14. Douglas H. Werner and SumanGanguly, "An Overview of Fractal Antenna Engineering Research",

15. IEEE Antenna and Propagation Magazine, Vol 45, No.1 February 2003

16. Peitgen, Jurgens, Saupe, "Chaos and Fractals New Frontiers of Science", Second Edition, Springer, New York, 2004.

17. B.B.Mandelbort, “The Fractal Geometry of Nature,” New York, W. H. Freeman, 1983.

18. Constantine A. Balanis, "Antenna Theory and design," Third edition, A John Wiley \$ Sons, Inc. Publication Rajshree, S. Sivasundarapandian and C.D. Suriyakala, "A modified sierpinski gasket triangular multiband fractal antenna for cognitive radio," Information Communication and Embedded Systems (ICICES), International Conference on, pp. 1-6, 2014.

19. D.S. Sagne, R.S. Batra and P.L. Zade, "Design of modified geometry Sierpinski carpet fractal antenna array for wireless communication," Advance Computing Conference (IACC), IEEE $3^{\text {rd }}$ International, pp. 435-439, 2013

20. S. Tripathi, A. Mohan and S. Yadav, "Hexagonal fractal ultra-wideband antenna using Koch geometry with bandwidth enhancement," Microwaves, Antennas \& Propagation, IET, vol. no. 8, iss. no. 15, pp. 1445-1450, 2014.

21. C. Ratnaratorn, N. Wongsin, C. Mahatthanajatuphat and P. Akkaraekthalin, "A multiband wide slotted antenna with Hilbert fractal slot on rectangular patch," Electrical Engineering/Electronics, Telecommunications and Information Technology (ECTICON), 10 ${ }^{\text {th }}$ International Conference on, pp. 1-4, 2013.

22. Sukhveer Singh" Design and Analysis of EShapeSierpinski Fractal Antenna" International Journal of Advanced Research in Electronics and Communication Engineering (IJARECE) Volume 4, Issue 8, August 2015

23. Sandeep Singh Sran "design of c shape modified sierpinski carpet fractal antenna for wireless applications"

24. International Conference on Electrical, Electronics, and Optimization Techniques (ICEEOT) 2016 